\title{
Detection of Mycobacterium tuberculosis in sputum from Suruí Indian subjects, Brazilian Amazon
}

\author{
Paulo Cesar Basta, Maraníbia AC O elemann*, Walter MR O elemann**, \\ Leila de Souza Fonseca**, Carlos EA Coimbra Jr/ ${ }^{+}$
}

\begin{abstract}
Escola Nacional de Saúde Pública Sérgio Arouca-Fiocruz, Rua Leopoldo Bulhões 1480, 21041-210 Rio de Janeiro, RJ, Brasil *Departamento de Micobacterioses, Instituto Oswaldo Cruz-Fiocruz, Rio de Janeiro, RJ, Brasil **Departamento de Imunologia, Instituto de Microbiologia Professor Paulo de Góes, Universidade Federal do Rio de Janeiro, Rio de Janeiro, RJ, Brasil

This investigation aimed at the detection of Mycobacterium tuberculosis (MTB) in the sputum of Surui Indian subjects from Amazonia, Brazil. Polymerase chain reaction analyses were positive for 12 samples, five of which were also culture-positive $(N=147)$. Four MTB genotypes were identified, one of which showed resistance to rifampicin and isoniazid. The study also highlighted one village complex as of particular importance, considering the relatively high number of tuberculosis cases reported and of MTB isolates obtained.
\end{abstract}

Key words: tuberculosis - epidemiology - drug resistance - South American Indians - genotyping

An incidence rate for tuberculosis (TB) among indigenous populations of the Brazilian Amazon that stands at over 300 cases per 100,000 inhabitants/year indicates a major health problem. Recent studies show that the incidence and case fatality rates for tuberculosis in the Brazilian Amazon may be over ten times higher among Indians than those observed among non-Indians living in the same region (Sousa et al. 1997, Escobar et al. 2001, Garnelo et al. 2003, Basta et al. 2004).

As part of an ongoing epidemiological study of tuberculosis in indigenous populations of southwestern Brazilian Amazon, we investigated sputum samples obtained from subjects who were screened as TB suspects during a population-based survey carried out among the Suruí Indians (Basta et al. 2006).

\section{STUDY POPULATION AND METHODS}

At the time of the fieldwork (May-August 2003), the Suruí numbered 920 individuals living in numerous villages at the Sete de Setembro Indian Reservation in the state of Rondônia, Brazilian Amazon $\left(60^{\circ}-61^{\circ} \mathrm{W}, 10^{\circ}-11^{\circ} \mathrm{S}\right)$. The average incidence of TB among the Suruí between 1991 and 2002 was 2,518.9 per 100,000 inhabitants, almost 50 times higher than the regional average, with nearly half the cases diagnosed in children $<15$ years old (Basta et al. 2004).

Spontaneously expectorated sputum was collected from all willing subjects who presented respiratory symptoms. Samples were kept under refrigeration for a maximum period of ten days, until they arrived at the laboratory in Rio de Janeiro. Unprocessed samples were first submitted to standard smear microscopic examination

Financial support: CNPq (grants 470850/2004-3), Instituto do Milênio, Ford Foundation

${ }^{+}$Corresponding author: carlos_coimbrajr@gbl.com.br

Received 10 October 2005

Accepted 2 August 2006 for acid-fast bacilli. The remaining sputum samples were decontaminated and liquefied according to the Petroff method $(4 \% \mathrm{NaOH})$. Subsequently, the samples were centrifuged $(3000 \times \mathrm{g}$ for $30 \mathrm{~min})$ and the cell-containing sediments re-suspended in $1 \mathrm{ml}$ of phosphate buffered saline (PBS). Two aliquots of $0.1 \mathrm{ml}$ were seeded on LöwensteinJensen medium and incubated for 60 days at $37^{\circ} \mathrm{C}$. MTB identification was carried out by standard biochemical and enzymatic tests (Kent \& Kubica 1985). Drug resistance tests were performed for rifampicin, isoniazid, streptomycin, ethambutol, and ethionamide with critical concentrations set at $0.2,40,4,2$, and $20 \mu \mathrm{g} / \mathrm{ml}$, respectively (Canetti et al. 1963). Resistance was diagnosed when the percentage of colonies exceeded $10 \%$ of the growth on a drugfree medium (streptomycin and ethionamide) or $1 \%$ (remaining drugs).

Sediments of processed sputum specimens were tested with AMPLICOR ${ }^{\circledR}$ M. tuberculosis (AMPLICOR MTB Roche Diagnostic Systems, NJ, US) following instructions of the manufacturer. However, due to the high number of inconclusive results initially obtained (44 samples), samples with inconclusive results were submitted to a modified protocol for assay-repetition by washing $100 \mu \mathrm{l}$ aliquots three times with $1 \mathrm{ml}$ of PBS containing $0.2 \%$ bovine serum albumin (known to sequester a variety of PCR inhibitors), followed by the wash step included in the standard protocol of the assay.

Ethical approval was obtained from the National Commission of Ethics in Research (Conep) of the National Health Council. A research permit was also obtained from the National Indian Foundation. Informed consent was obtained from village leaders, since most subjects were not literate in Portuguese.

Mycobacterial interspersed repetitive units-variablenumber tandem repeats (MIRU-VNTR) and spoligotyping analysis - Extraction of DNA from mycobacterial strains followed Ausubel et al. (2002). Clusters were defined as groups of patients with MTB strains showing identical MIRU-VNTR (the same canonical number for 12-loci MIRU-VNTR) and spoligotype patterns. Spoligotyping 
of isolates was performed as described by Kamerbeek et al. (1997).

MTB isolates were typed by the minisatellite typing method based on variable-number tandem repeats (VNTR) of mycobacterial interspersed repetitive units (MIRUs) (Supply et al. 2001). Each MIRU locus was individually amplified in a $25 \mu \mathrm{l}$ volume from 10-25 ng of DNA using published primers (Supply et al. 2001). After electrophoresis the stained gels were analyzed by visual inspection. The 12 MIRU-VNTR alleles were assigned according to an allelic table (Mazars et al. 2001).

\section{RESULTS AND DISCUSSION}

The culture of 147 sputum samples (from 109 subjects) yielded five MTB isolates. PCR analyses were positive for 12 samples (including all MTB culture-positive isolates), negative for 102 samples, and consistently inconclusive for 33 samples. The modified wash procedure allowed for the resolution of 11 of 44 initially inconclusive samples.

All culture-positive cases were treated in accordance with protocols put forth by the Brazilian National Tuberculosis Program. PCR-positive cases only were reevaluated three months later and active TB was not confirmed in these subjects.

This is the first study of MTB transmission by genotyping in an indigenous population in southwestern Amazonia. Previous work on the subject was carried out in the extreme north of the region, among the Yanomami Indians, and identified two genotypes (Sousa et al. 1997). In the present study, molecular genotyping analysis was only carried-out in the five culture-positive isolates. We identified one cluster of two out of four distinct MTB genotypes, one of which also presented resistance to standard drugs.

Clusters were defined considering $100 \%$ of identity among MIRU-VNTR patterns and spoligotypes and were assumed to have arisen from recent transmission. As shown in the Table, two of the five isolates were obtained from Suruí women (subjects A and B) living in the Linha 14 village and represent a cluster in virtue of their identical MIRU-VNTR and spoligotyping genotypes. The remaining isolates show unique genotypes differing in four MIRU loci (subjects $C$ and $E$ ) and three MIRU loci (subject $D$ ) from the identified cluster. The isolate from subject C, also from Linha 14, differs in MIRU-4, -16, -23, and -40. The isolate from subject $\mathrm{D}$, who lives in the village Placa, is rifampicin and isoniazid resistant and differs from the cluster in MIRU-10, -16, and -27. The distance between Linha 14 and Placa is approximately $3 \mathrm{~km}$ and their inhabitants interact frequently. The genotype from subject E's isolate differs from the cluster in MIRU-16, $-23,-26$, and -40 . His village (Linha 8 ) is located about $30 \mathrm{~km}$ away from Linha 14 and social interaction between inhabitants of the two villages is sporadic.

All five isolates presented LAM genotypes and possessed one repeat at MIRU locus 24, indicative for the modern group of MTB (Beijing, Haarlem, LAM). The number of typed isolates is too small to draw major conclusions regarding possible transmission chains. Notwithstanding, some considerations may be advanced.

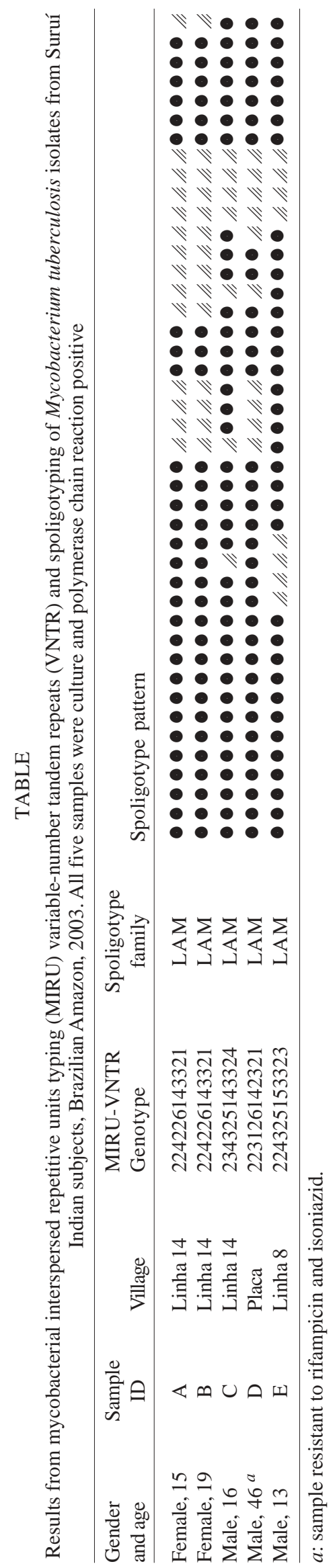


The results suggest recent TB transmission in two subjects (A and B) from the same village, in view of their confirmed epidemiological link. Although all isolates were grouped as members of the LAM genotype MTB family (Brudey et al. 2006), the diversity in spoligopatterns and MIRU-VNTR suggests that these strains have had sufficient time to diversify over the years. Therefore, the LAM spoligotype is likely to have been introduced in the Suruí some time ago.

We have performed a search in a MTB database, available through the Institute Pasteur of Guadaloupe (The SITVIT Database available at: http://www.pasteurguadeloupe.fr), which includes spoligotypes and MIRUVNTR patterns. By comparing the spoligotype found in the isolate from patient $\mathrm{E}$ with spoligotypes available in the database, we found a $100 \%$ pattern match. The spoligotype shared-type (SIT) 102 and VNTR-MIRU-type (VIT) 33 has been found in 54 clinical isolates retrieved worldwide in a frequency of 11/54 (New York, US), 6/54 (Pretoria, South Africa), 5/54 (Brasília, Brazil) and 3/54 (Buenos Aires, Argentina). The VNTR-MIRU pattern was found in 139 clinical worldwide isolates, mostly in the US. The isolate from patient D matches spoligotype SIT 1758, found in 8 MTB clinical isolates from Brazil (7/8) and Portugal (1/8). No matches were found in the database for the VNTR-MIRU VIT of patient's D isolate. These observations suggest that the MTB isolates from patients D and $\mathrm{E}$ are distributed worldwide and participate in chains of transmission in the Brazilian general population. According to our database query, both isolates have been previously found in TB patients from Brasília.

The study also highlights the village complex of Linha 14-Placa as of particular importance in the epidemiology of TB in the Suruí population, considering the possible clustering of MTB isolates. As it has been noted elsewhere, this village complex that maintains intense social exchange, not only concentrates nearly all TB cases identified in this survey (Basta et al. 2006), but it also accounts for close to half of all prior cases reported among the Suruí (Basta et al. 2004). Although at present this constitutes the largest Suruí village, concentrating circa $20 \%$ of the total population, further studies remain to be done in order to clarify MTB transmission patterns in this population.

The study of TB transmission by genotyping in indigenous populations in Amazonia deserves more attention and should be repeated with a greater number of isolates in order to allow for a better understanding of TB epidemiology in these populations.

\section{ACKNOWLEDGEMENTS}

To Dr Ricardo V Santos from Fiocruz for critically reading the manuscript. To Dr Phillip Suffys for the facilities at the Laboratory of Molecular Biology Applied to Mycobacteria, Fiocruz. To Dr Pablo Bifani for providing support and access to the Laboratory of Molecular Pathology of Tuberculosis, Pasteur Institute of Brussels, and for having helped to improve the manuscript. To Marlei G Silva and Samantha B Ribeiro for their technical assistance in the isolation of MTB strains and PCR amplification. The local staff of the Fundação Nacional de Saúde provided key logistic support.

\section{REFERENCES}

Ausubel F, R Brent, RE Kingston, DD Moore, JG Seidman, JA Smith, K Struhl 2002. Short Protocols in Molecular Biology, 5th ed., John Wiley \& Sons, New York.

Basta PC, Coimbra Jr. CEA, Escobar AL, Santos RV 2004. Aspectos epidemiológicos da tuberculose na população indígena Suruí, Amazônia, Brasil. Rev Soc Bras Med Trop 37: 338-342.

Basta PC, Coimbra Jr. CEA, Escobar AL, Santos RV, Alves LCC, Fonseca LS 2006. Survey for tuberculosis in an indigenous population of Amazonia: the Suruí of Rondônia, Brazil. Trans R Soc Trop Med Hyg 100: 579-585.

Brudey K, Driscoll JR, Rigouts L, Prodinger WM, Gori A, AlHajoj SA, Allix C, Aristimuno L, Arora J, Baumanis V, Binder L, Cafrune P, Cataldi A, Cheong S, Diel R, Ellermeier C, Evans JT, Fauville-Dufaux M, Ferdinand S, Garcia de Viedma D, Garzelli C, Gazzola L, Gomes HM, Guttierez MC, Hawkey PM, van Helden PD, Kadival GV, Kreiswirth BN, Kremer K, Kubin M, Kulkarni SP, Liens B, Lillebaek T, Ho ML, Martin C, Martin C, Mokrousov I, Narvskaia O, Ngeow YF, Naumann L, Niemann S, Parwati I, Rahim Z, Rasolofo-Razanamparany V, Rasolonavalona T, Rossetti ML, Rusch-Gerdes S, Sajduda A, Samper S, Shemyakin IG, Singh UB, Somoskovi A, Skuce RA, van Soolingen D, Streicher EM, Suffys PN, Tortoli E, Tracevska T, Vincent V, Victor TC, Warren RM, Yap SF, Zaman K, Portaels F, Rastogi N, Sola C 2006. Mycobacterium tuberculosis complex genetic diversity: mining the fourth international spoligotyping database (SpolDB4) for classification, population genetics and epidemiology. BMC Microbiol 6: 23.

Canetti G, Rist N, Grosset J 1963. Mesure de la sensibilité du bacille tuberculeux aux drogues antibacillaires par la méthode des proportions. Méthodologie, critères de résistance, résultats, interprétation. Rev Tuberc Pneumol (Paris) 27: 217-272.

Escobar AL, Coimbra Jr CEA, Camacho LA, Portela MC 2001. Tuberculose em populações indígenas de Rondônia, Amazônia, Brasil. Cad Saúde Públ 17: 285-298.

Garnelo L, Macedo G, Brandão LC 2003. Os Povos Indígenas e a Construção das Políticas de Saúde no Brasil, Pan American Health Organization, Brasília.

Kamerbeek J, Schouls L, Kolk A, van Agterveld M, van Soolingen D, Kuijper S, Bunschoten A, Molhuizen H, Schaw R, Goyal M, van Embden JDA 1997. Simultaneous detection and strain differentiation of Mycobacterium tuberculosis for diagnosis and epidemiology. J Clin Microbiol 35: 907-914.

Kent PT, Kubica GP 1985. Public Health Mycobacteriology: A Guide for the Level III Laboratory, Centers for Disease Control, Atlanta.

Mazars E, Lesjean S, Banuls AL, Gilbert M, Vincent V, Gicquel B, Tibayrenc M, Locht C, Supply P 2001. High resolution minisatellite-based typing as a portable approach to global analysis of Mycobacterium tuberculosis molecular epidemiology. Proc Natl Acad Sci USA 98: 1901-1906.

Sousa AO, Salem J, Lee F, Verçosa M, Cruaud P, Bloom B, Lagrange P, David HL 1997. An epidemic of tuberculosis with a high rate of tuberculin anergy among a population previously unexposed to tuberculosis, the Yanomami Indi- 
ans of the Brazilian Amazon. Proc Natl Acad Sci USA 94: 13227-13232.

Supply P, Lesjean S, Savine E, Kremer K, van Soolingen D,
Locht C 2001. Automated high-throughput genotyping for study of global epidemiology of Mycobacterium tuberculosis based on mycobacterial interspersed repetitive units. $J$ Clin Microbiol 39: 3563-71. 